www.jmscr.igmpublication.org

Impact Factor (SJIF): 6.379

Index Copernicus Value: 79.54

ISSN (e)-2347-176x ISSN (p) 2455-0450

crossrefDOI: https://dx.doi.org/10.18535/jmscr/v6i9.119

Journal Of Medical Science And Clinical Research

IGM Publication

An Official Publication of IGM Publication

\title{
A Cross- Sectional Study to Assess the Extent of Helicopter Parenting in Adolescent Age Group
}

\author{
Authors \\ Dr Veena Yesikar ${ }^{1}$, Dr Ruchita Banseria ${ }^{2}$, Dr Sanjay Dixit ${ }^{3}$, Dr Amit Gharia ${ }^{4}$, \\ Dr Yogesh Chouhan ${ }^{5}$ \\ ${ }^{1}$ Associate Professor, Department of Community Medicine, MGM Medical College, Indore \\ ${ }^{2,5}$ Resident, Department of Community Medicine, MGM Medical College, Indore \\ ${ }^{3}$ Professor, Department of Community Medicine, MGM Medical College, Indore \\ ${ }^{4}$ Demonstrator, Department of Community Medicine, MGM Medical College, Indore \\ Corresponding Author \\ Dr Ruchita Banseria \\ Resident, Department of Community Medicine, MGM Medical College, Indore, (M.P), India \\ Email: ruchibanseria@gmail.com
}

Abstract
"Helicopter parenting "or cosseting parent is a term used to describe a phenomenon of a growing
number of parents, who pays extremely close attention and obsessed with their children's success
particularly at areas of decision making, academic institutions, and social relationships. This was a
cross-sectional study. Systematic sampling method is used for selection of sample for this every $3^{\text {rd }}$ student
is taken. 100 students are selected from each institute, so total 200 students and 200 parents are taken for
the study this makes sample size of 400. The respondent parents had a mean age of 47.1 years and $62 \%$
were female and 38\% male. $98 \%$ were the biological parent of the young adult child who participated
along with them in the study, with the remaining $2 \%$ includes stepparents, adoptive parents, and
grandparents who had legal guardianship when the young adult child was a minor. Behavioural based
measures of Helicopter parenting and its various aspects were assessed by semi-structured questions over
parent and child separately with responses on a 5-point Likert scale (1= never, $2=$ rarely, $3=$ sometimes,
$4=$ frequently, $5=$ always). Internal reliabilities were $\alpha=.72$ for young adult children and $\alpha=.71$ for
parents. Parenting skills differ from individual to individual; it also depends on various factors such as
education status, socio-economic status, family size, birth order, etc. There should also be gatherings and
group discussions in community for parents for better understanding of parenthood. Helicopter parenting
is a new concept but as there is no universal definition it is important for future studies to determine and
investigate the elements involved in it.

\section{Introduction}

"Helicopter parenting "or cosseting parent is a term used to describe a phenomenon of a growing number of parents, who pays extremely close attention and obsessed with their children's success particularly at areas of decision making, academic institutions, and social relationships ${ }^{1}$. Helicopter parenting involves various forms of hovering; this parenting practice could theoretically occur at any stage of childhood, it is 
most often used in reference to parent's of late adolescent or young adult children. ${ }^{2}$

Parental support and engagement in a child's life has generally been considered positive for their mental and social growth. But micromanaging every aspect of their child lives preventing them to learn from their own mistakes. Also parents who always shields and solve problems for their child preventing their children to experience failure or challenges in life.

However in recent years, perceptions of highlyinvolved parents have shifted from supportive to over-intrusive. As in very young children, it has been linked to anxious, depressive, and insecure tendencies. ${ }^{3,4}$ In young adults, over parenting is linked to problems with emotional regulation and management, especially in the areas of depression and frustration. ${ }^{5}$

Present study is being conducted with the aim to study the extent of helicopter parenting among adolescent age group, to find positive and negative aspects of helicopter parenting on the child and to assess the effect caused by helicopter parenting practice on child's future.

\section{Methodology}

This was a cross-sectional study conducted for period of 4 months in 2 randomly selected coaching institutes. Study sample consists of students of adolescent age group 10-19 years and their parents or guardians. Systematic sampling method is used for selection of sample for this every $3^{\text {rd }}$ student is taken. 100 students are selected from each institute, so total 200 students and 200 parents are taken for the study this makes sample size of 400. Educational purpose of study is explained and verbal consent is taken from study sample. Semi-structured questionnaire is used as a study tool containing demographics and questions related to access the extent of helicopter parenting on various variables. Qualitative interviews were taken from those who gave informed consent, response options were on a 5point Likert scale ( $1=$ never, $5=$ always $)$ the scale has 10 items. All statistical analyses were done in SPSS (version 20, IBM SPSS Statistics).

\section{Results}

Participants in this investigation were 400 (200 students and their 200 parents respectively). Parent-child pair was included through randomly selected students attending coaching institutes. The respondent parents had a mean age of 47.1 years and $62 \%$ were female and $38 \%$ male. $98 \%$ were the biological parent of the young adult child who participated along with them in the study, with the remaining $2 \%$ includes stepparents, adoptive parents, and grandparents who had legal guardianship when the young adult child was a minor. Religion wise sample was 56\% Hindu $13 \%$ Muslims 14\% Sikhs and 17\% Christians. In terms of family size, $14 \%$ of the parents had one child, $47 \%$ had two children, $28 \%$ had three children and $11 \%$ had four or more. The parents-child pair in terms of socio-economic status $32 \%$ belongs to high class, $44 \%$ of middle class and $24 \%$ of low class.

Independent sample T-test and one way ANOVA was applied in order to see the group differences between the scale measures of Helicopter parenting and variables such as sex, class, religion, family size and birth order. Significant value $(\mathrm{p}<0.05)$ was seen only in sex variable and family size variable. Male participants' perceptions of their parents as helicopter parents were more than female participants $(\mathrm{p}=0.023)$. Family size shows significant difference $(\mathrm{p}=0.011)$ parents having one child or two children $(78 \%)$ followed by more children $(22 \%)$ shows more effect of Helicopter parenting.

The young adult children who participated in this investigation were, on average, 16.23 years of age with $57 \%$ male and $43 \%$ female. In terms of birth order, $34 \%$ of the children described themselves as the oldest, $17 \%$ middle, $39 \%$ youngest, and $10 \%$ as single child. With respect to living condition $78 \%$ children were living with parents, $13 \%$ with roommates far from home, and $9 \%$ living alone. 
Table 1: To assess the frequency of communication between child and parents by asking how many times do they communicate and responses were 53\% once a day 14\% several times a day 13\% once a week, $19 \%$ several times a month and $1 \%$ once a month or less.

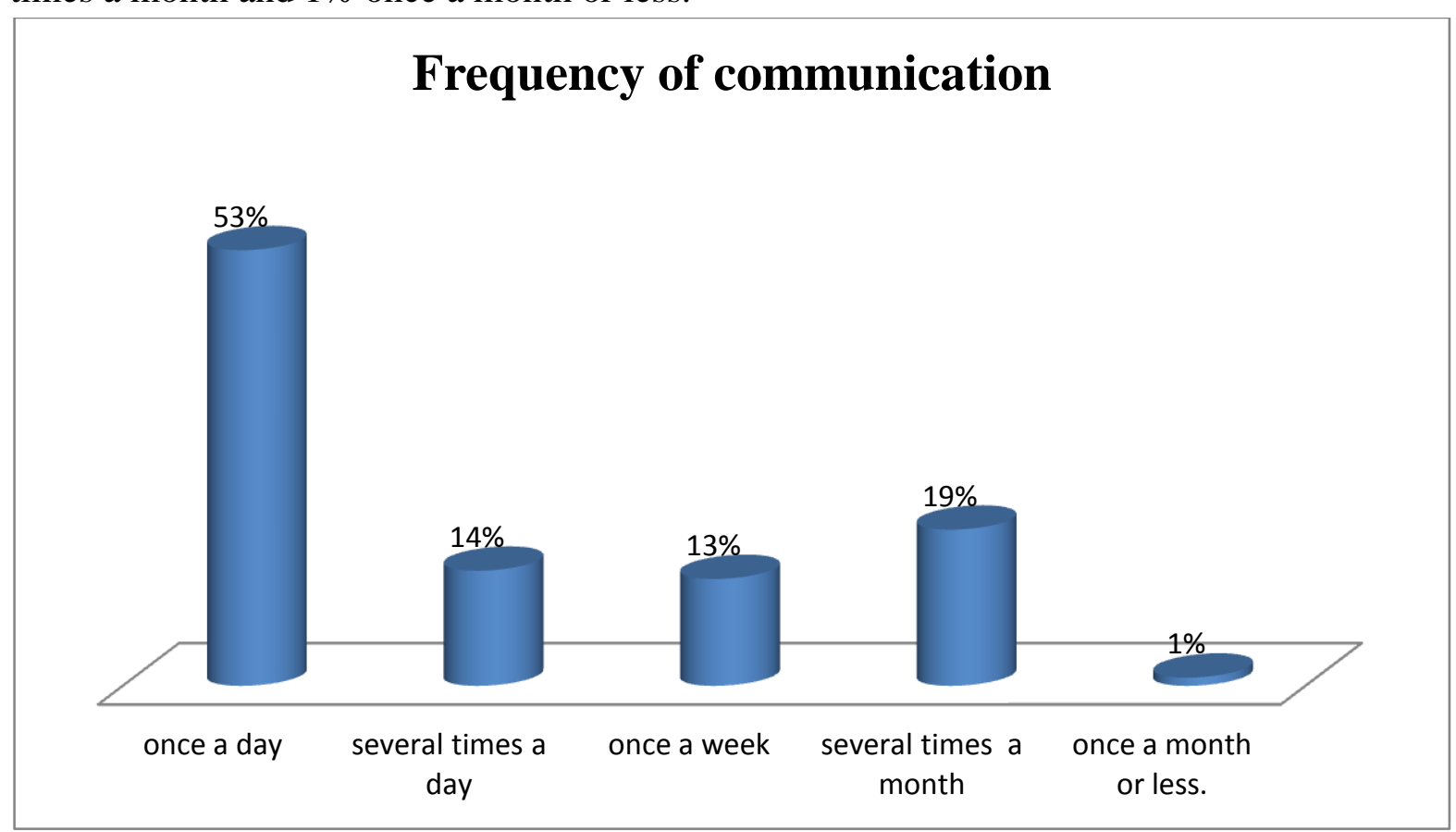

Behavioural based measures of Helicopter parenting and its various aspects were assessed by semi-structured questions over parent and child separately with responses on a 5-point Likert scale (1= never, $2=$ rarely, $3=$ sometimes, $4=$ frequently, $5=$ always). Internal reliabilities were $\alpha=.72$ for young adult children and $\alpha=.71$ for parents.

$58 \%$ had a friendly talk with their child, $52 \%$ parents/ guardian knew the passwords and regularly checked their social networking stuff. 49\% always attended the parent teachers meetings, parent/teacher conferences, or other meeting, $43 \%$ always accompanied their children most of the places where they went in market, parties etc. $57 \%$ parents frequently asked their child about his/her future and career plans. 54\% young adults of study sample choose their career by their parent's choice. $45 \%$ parent/guardians always try to make all of major decisions. $49 \%$ of parents choose friends for their children. 68\% parent /guardians always insisted that their child keep them informed of their daily activities. $71 \%$ parent /guardians always try to fix any difficult situation their child going through. 52\% children give statement that they cannot do anything without their parent's help, while $57 \%$ children thought that their parents want to change them accordingly.

\section{Discussion}

The current study is an investigation of the role of parental involvement and helicopter parenting. This study includes young adult i.e. adolescent age group, to date the majority of research into the construct of helicopter parenting has focused on adolescents and emerging adults $2,6,7$

The parents had a mean age of 47.1 years and $62 \%$ were female and $38 \%$ male, mainly mothers were involved in this study but it will be better if both mother and father would interviewed separately.

In terms of family size, $14 \%$ of the parents had one child, $47 \%$ had two children, $28 \%$ had three children and $11 \%$ had four or more children. Family size shows significant difference $(\mathrm{p}=0.011)$ parents having one or two child shows more effect of Helicopter parenting, which may be due to lack of time and more responsibilities because of more children.

With respect to gender; Male participants' perceptions of their parents as helicopter parents are more than female participants $(\mathrm{p}=0.023)$ this 
could be because of Indian culture which consider males as old age support so they should be monitored from very beginning. Various studies suggest that more support of parents is due to foster their successes, because they get along well with those children, or because they expect those children to give support to them in the future $8,9,10$ Our study shows that about $71 \%$ parent /guardians always tries to fix any difficult situation their child going through, $45 \%$ parent/guardians always tries to make all of major decisions of their child and $52 \%$ children give statement that they cannot do anything without their parent's help shows half of children were dependent on parents for solving problems, which interfere with child learning and development. This finding also goes with the study done by Lipka (2005), Taylor (2007) ${ }^{11,12}$. Also the study done by Marano (2008) believes that when parents constantly trying to solve problems and take decisions for their children they lose the opportunity to build important traits like self-regulation and self-efficacy among them. ${ }^{13}$ So if children actually encounter any problems in life then they are incapable of taking decisions and are more likely to fail. But as we see in studies done by Berkman (2000), Cohen (2004), Uchino (2009) that intense support and involvement of parents typically manifest better well-being of their children ${ }^{14,15,16}$.Thus, we conclude that children who received intense support would have better well-being than those children who did not receive such support, particularly if they viewed that support favourably. However relationship between overparenting and childhood anxiety could not assessed properly in present study but according to study done by Ragnell (2011) it is one of the most common disorders in children ${ }^{17}$

Parenting skills differ from individual to individual; it also depends on various factors such as education status, socio-economic status, family size, birth order, etc. This study was conducted to reveal the extent of helicopter parenting and its effect on parent child attachment which showed that parents of urban areas showed more signs of positive parenting as compared to parents of slum area. Parents of urban areas were more involved with their child and were more attached to them as compared to that of slum area. This may pertain to their low socio-economic status and low education status which resulted in development of gap in parent and their child.

From this study it can conclude that normal parenting styles can result in positive youth outcomes, such as adjustment and competence ${ }^{18}$ while over parenting can lead to variety of negative youth outcomes ${ }^{6}$ such as poor selfregulation and childhood anxiety 2,19 . We recommend that there should be more communication between parent and child. Parents should understand about their child's feeling. Children should understand the concerns of their parents about them and should respect their moral values. There should be special sessions and seminars in school for children. There should also be gatherings and group discussions in community for parents for better understanding of parenthood. Due to limitation of sample size and limitation of resources it was unable to examine all possible components of helicopter parenting. Helicopter parenting is a new concept but as there is no universal definition it is important for future studies to determine and investigate the elements involved in it.

\section{References}

1. Shoup et al, Helicopter Parents: Examining the Impact of Highly Involved Parents on Student Engagement and Educational, June 2009, Indiana University Paper presented at the 49th Annual Forum of the Association for Institutional Research Atlanta, Georgia

2. Segrin et al (2012) The association between overparenting, parent-child communication, and entitlement and adaptive traits in adult children. Family Relations, 61, 237-252.

3. Bayer, J., Sanson, A., \& Hemphill, S. (2006). Parent influences on early childhood internalizing difficulties. Journal 
of Applied Developmental Psychology, 27, 542-559.

4. Hudson et al (2008). Child and maternal influence on parenting behaviour in clinically anxious children. Journal of Clinical Child Adolescent Psychology. 2009 Mar; 38(2):256-62. doi: 10.1080/15374410802698438.

5. Fischer, J.L., Forthun, L.F., Pidcock, B.W. et al. J Youth Adolescence (2007) 36: 912. https://doi.org/10.1007/s10964-006-91266.

6. Padilla-Walker, L.M., \& Nelson, L.J. (2012). Black hawk down?: Establishing helicopter parenting as a distinct construct from other forms of parental control during emerging adulthood. Journal of Adolescence, 35, 1177-1190.

7. Segrin, C., Woszidlo, A., Givertz, M., \& Montgomery, N. (2013). Parent and child traits associated with overparenting. Journal of Social and Clinical Psychology, 32(6), 569-595.

8. Fingerman K, Miller L, Birditt K, Zarit S. Giving to the Good and the Needy: Parental Support of Grown Children. Journal of marriage and the family. 2009;71(5):1220-1233. doi:10.1111/j.1741-3737.2009.00665.

9. Pillemer \& Suitor, 2006; Making Choices: A Within-Family Study of Caregiver Selection The Gerontologist, Volume 46, Issue 4, 1 August 2006, Pages 439-448, https://doi.org/10.1093/geront/46.4.439

10. Silverstein et al Reciprocity in parent-child relations over the adult life course. J Gerontol B Psychol Sci Soc Sci. 2002 Jan;57(1):S3-13.

11. Lipka, S. (2005, December 16). Some helicopter parents play politics to protect their children's interests. The Chronicle of Higher Education, 52(17), A22.
12. Taylor, M. (2006). Helicopters, Snowplows, and Bulldozers: Managing Students' Parents. The Bulletin, 74(6), 1321.

13. Marano HE. A Nation of Wimps: The High Cost of Invasive Parenting. New York, NY: Broadway Books; 2008

14. Berkman et al, From social integration to health: Durkheim in the new millennium. Social Science \& Medicine 2000 Sep;51(6):843-57.

15. Cohen; Social relationships and health, American Psychologist. 2004 Nov; 59(8):676-684. doi: 10.1037/0003066X.59.8.676.

16. Uchino BN. What a Lifespan Approach Might Tell Us about Why Distinct Measures of Social Support have Differential Links to Physical Health. Journal of social and personal relationships. 2009;26(1):53-62. doi:10.1177/0265407509105521

17. Ragnell, A.L. (2011). Anxiety and separation disorders. Pediatrics in Review, 32(10), 440-446.

18. Baumrind, D. (2005). Patterns of parental authority and adolescent autonomy. New Directions for Child and Adolescent Development, 108, 61-69.

19. Sideridis, \& Kafetsios, Perceived parental bonding, fear of failure and stress during class presentations International Journal of Behavioral Development 2008, Vol 32, Issue 2, pp. 119 - 130. 